\title{
Aura Microwave Limb Sounder observations of dynamics and transport during the record-breaking 2009 Arctic stratospheric major warming
}

\author{
Gloria L. Manney, ${ }^{1,2}$ Michael J. Schwartz, ${ }^{1}$ Kirstin Krüger, ${ }^{3}$ Michelle L. Santee, ${ }^{1}$ \\ Steven Pawson, ${ }^{4}$ Jae N. Lee, ${ }^{1}$ William H. Daffer, ${ }^{1}$ Ryan A. Fuller, ${ }^{1}$ \\ and Nathaniel J. Livesey ${ }^{1}$ \\ Received 10 April 2009; accepted 27 May 2009; published 27 June 2009
}

[1] A major stratospheric sudden warming (SSW) in January 2009 was the strongest and most prolonged on record. Aura Microwave Limb Sounder (MLS) observations are used to provide an overview of dynamics and transport during the $2009 \mathrm{SSW}$, and to compare with the intense, long-lasting SSW in January 2006. The Arctic polar vortex split during the 2009 SSW, whereas the 2006 SSW was a vortex displacement event. Winds reversed to easterly more rapidly and reverted to westerly more slowly in 2009 than in 2006. More mixing of trace gases out of the vortex during the decay of the vortex fragments, and less before the fulfillment of major SSW criteria, was seen in 2009 than in 2006; persistent well-defined fragments of vortex and anticyclone air were more prevalent in 2009. The 2009 SSW had a more profound impact on the lower stratosphere than any previously observed SSW, with no significant recovery of the vortex in that region. The stratopause breakdown and subsequent reformation at very high altitude, accompanied by enhanced descent into a rapidly strengthening upper stratospheric vortex, were similar in 2009 and 2006. Many differences between 2006 and 2009 appear to be related to the different character of the SSWs in the two years. Citation: Manney, G. L., M. J. Schwartz, K. Krüger, M. L. Santee, S. Pawson, J. N. Lee, W. H. Daffer, R. A. Fuller, and N. J. Livesey (2009), Aura Microwave Limb Sounder observations of dynamics and transport during the record-breaking 2009 Arctic stratospheric major warming, Geophys. Res. Lett., 36, L12815, doi:10.1029/2009GL038586.

\section{Introduction}

[2] Major stratospheric sudden warmings (SSW) dramatically disrupt the typical wintertime circulation of the stratosphere and mesosphere. They are triggered by anomalous wave activity propagating from the upper troposphere and may, in turn, affect tropospheric weather patterns [e.g., Baldwin and Dunkerton, 2001]. Climate-change induced alterations in SSW frequency and characteristics are expected due to changes in the Brewer-Dobson circulation, and such

\footnotetext{
${ }^{1}$ Jet Propulsion Laboratory, California Institute of Technology, Pasadena, California, USA.

${ }^{2}$ Also at New Mexico Institute of Mining and Technology, Socorro, New Mexico, USA.

${ }^{3}$ Leibniz Institute for Marine Sciences at Kiel University, Kiel, Germany.

${ }^{4}$ NASA Goddard Space Flight Center, Greenbelt, Maryland, USA.
}

Copyright 2009 by the American Geophysical Union. 0094-8276/09/2009GL038586\$05.00 changes will in turn impact stratospheric ozone $\left(\mathrm{O}_{3}\right)$ loss and recovery and tropospheric climate [e.g., Charlton-Perez et al., 2008; World Meteorological Organization, 2007]. Only in the past few years have sufficient data been available to thoroughly study dynamics and transport during SSWs from the upper troposphere through the mesosphere. An unusually strong, prolonged SSW in January 2006 was the first to be characterized in detail using recent data sets: Upward propagating waves generated above a ridge in mid-January 2006 led to a breakdown of the stratospheric vortex [Coy et al., 2009], with criteria for a major SSW (10 hPa zonal mean winds and temperature gradient reversal poleward of $\left.60^{\circ} \mathrm{N}\right)$ fulfilled on 21 January [e.g., Manney et al., 2008b] (hereinafter referred to as M08). The stratopause broke down during the SSW, then reformed at very high altitude (near $75 \mathrm{~km}$ ) [M08; Siskind et al., 2007]. Trace gas observations indicate enhanced descent into a strong reformed upper stratospheric/ lower mesospheric (USLM) vortex [e.g., Randall et al., 2006; Manney et al., 2008a, 2009]. Manney et al. [2009] (hereinafter referred to as M09) used Aura Microwave Limb Sounder (MLS) and Atmospheric Chemistry ExperimentFourier Transform Spectrometer data, with chemistry transport model simulations and meteorological analyses from a data assimilation system (DAS), to study transport during the 2006 SSW throughout the upper troposphere and middle atmosphere.

[3] SSWs can be classified as vortex displacement or vortex split events [e.g., Charlton and Polvani, 2007] (hereinafter referred to as CP07). The $2006 \mathrm{SSW}$ was a vortex displacement event (M08). In January 2009, another very strong prolonged major SSW occurred, this time a vortex split event. The major SSW criteria were fulfilled on 24 January. Differences are expected in dynamics and transport between vortex split and vortex displacement events. We use temperature, geopotential height and trace gas data from Aura MLS, with meteorological fields from the Goddard Earth Observing System-Version 5.2.0 (GEOS-5) DAS, to survey dynamics and transport during the 2009 SSW and to present initial comparisons with the 2006 SSW. The MLS and DAS fields and analysis methods are described by M08 and M09.

\section{Dynamical Overview}

[4] Figure 1 gives an overview of dynamics during the 2009 SSW using MLS temperature and geopotential height (Z) data [Schwartz et al., 2008]; winds and static stability are calculated as described by M08. Starting on $\sim 9$ January, unusually high values of maximum $45-55^{\circ} \mathrm{N} 147 \mathrm{hPa} \mathrm{Z}$ 


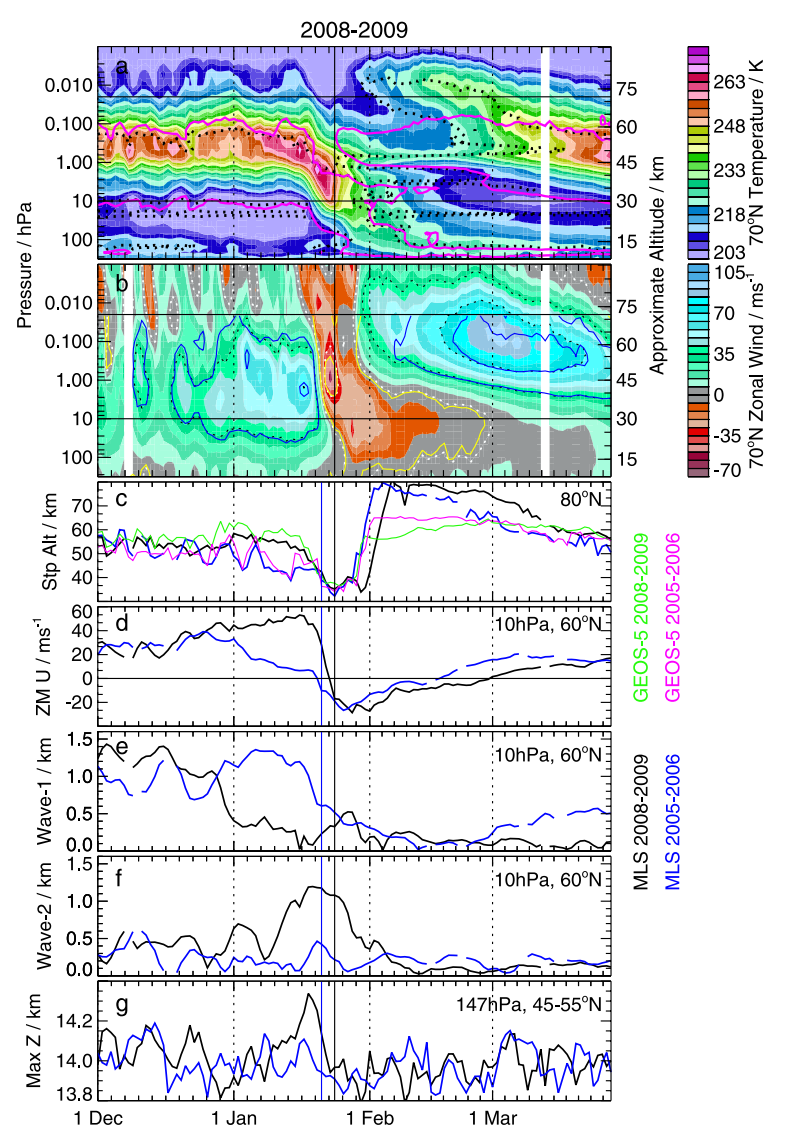

Figure 1. $70^{\circ} \mathrm{N}$ pressure-time sections of (a) MLS zonal mean temperature (overlays: MLS (black dashed) and GEOS-5 (magenta) $4 \times 10^{-4} \mathrm{~s}^{-2}$ static stability) and (b) MLS-derived zonal mean wind (overlays: MLS (white/ black dashed) and GEOS-5 (yellow/blue) -35, 0, 35, $70 \mathrm{~ms}^{-1}$ winds. Thin horizontal lines in Figures $1 \mathrm{a}$ and $1 \mathrm{~b}$ are at 0.02 (highest level with GEOS-5 data) and $10 \mathrm{hPa}$ (where major SSW criteria are defined). (c) The $80^{\circ} \mathrm{N}$ MLS (2009 black/2006 blue) and GEOS-5 (2009 green/2006 magenta) stratopause altitudes. (d) The $10-\mathrm{hPa}, 60^{\circ} \mathrm{N}$ MLS-derived zonal mean winds. (e) Wave 1 and (f) wave $210-\mathrm{hPa}, 60^{\circ} \mathrm{N}$ MLS geopotential height (Z) amplitudes. (g) Maximum MLS $147 \mathrm{hPa} Z$ between 45 and $55^{\circ} \mathrm{N}$. Figures $1 \mathrm{~d}-1 \mathrm{~g}$ show 2008-2009 in black, 2005-2006 in blue; black/blue vertical lines show date when major SSW criteria were first met in 2009/2006.

(Figure 1g) appeared. A sharp peak in mid-January to highly anomalous values was accompanied by strong wave- 2 amplification in the midstratosphere (Figure 1f), and a subsequent rapid drop in $60^{\circ} \mathrm{N}$ zonal mean wind (Figure 1d). Similar to the evolution in 2006 (M08), the stratopause warmed and dropped as the SSW developed (Figure 1a, 1c), then broke down, leading to a nearly isothermal middle atmosphere at the end of January. The stratopause identification algorithm does not search for temperature maxima below $30 \mathrm{~km}$. Arguably, the stratopause - the primary temperature maximum - might be identified as being near $15 \mathrm{~km}$ in late January 2009. In 2006, the primary temperature maximum dropped to $\sim 30 \mathrm{~km}$. In early February, the polar stratopause reformed at very high altitude, near $80 \mathrm{~km}$ at $80^{\circ} \mathrm{N}$, in both 2006 and 2009 (Figure 1c). As in 2006, the
GEOS-5 (and other) DAS failed to capture the behavior of the stratopause after the $2009 \mathrm{SSW}$, placing the altitude of reformation too low (Figures 1a and 1c).

[5] In the mesosphere, several brief wind reversals preceded the one associated with the major SSW. Mesospheric easterlies related to the SSW occurred 8-10 days before the middle stratospheric wind reversal (Figure 1b). The mesospheric wind reversal was gradual compared to the rapid transition from strong westerlies to strong easterlies in the middle and upper stratosphere. The wind reversal was later (typical of SSWs) and more prolonged at lower altitudes. As in 2006, the vortex reformed strongly and quickly in the USLM and weakly in the middle stratosphere. Consistent with the failings in temperatures, GEOS-5 USLM winds accelerate too slowly after the SSW. The 2009 SSW had a deeper influence than that in 2006, with wind reversals extending below $300 \mathrm{hPa}$ during the $\mathrm{SSW}$ and near zero winds persisting through March below $\sim 20 \mathrm{~km}$ (in 2006, easterlies extended only down to $\sim 100 \mathrm{hPa}$, and westerlies reappeared at all levels by $\sim 20$ February (M08)).

[6] Contrasts and similarities emerge between the dynamics of the 2006 and 2009 SSWs (blue lines in Figures 1c-1g show behavior in 2005-2006). The breakdown and reappearance of the stratopause and reformation of the USLM vortex were very similar (e.g., Figure 1c), consistent with CP07's finding of similar temperature evolution during vortex split and vortex displacement SSWs. Very large wave-1 (wave-2) during the SSW in 2006 (2009) (Figures 1e and 1f) is consistent with vortex displacement (split) events. December wave-1 amplitudes were large in both years. Wave-1 minor SSWs preceding a major SSW are also often associated with "pre-conditioning", i.e., changes in the zonal flow that focus upward propagating waves poleward and decelerate winds in the middle to upper stratosphere, triggering a SSW [e.g., Labitzke, 1981; Andrews et al., 1987]. Wave-1 amplitudes were larger prior to the 2009 SSW, suggesting a larger role of preconditioning. Deceleration of the $60^{\circ} \mathrm{N}$ winds in 2009 was more rapid than that in 2006 (Figure 1d), and they recovered more slowly afterward. These differences in dynamics are consistent with differing characteristics of vortex split and vortex displacement events described by CP07.

[7] $147 \mathrm{hPa}$ MLS midlatitude $\mathrm{Z}$ maxima (Figure 1g) showed several significant peaks in January 2006, with the maximum near mid-January associated with an eastwardpropagating ridge forcing changes that focused propagating waves poleward [Coy et al., 2009]. In 2009, high Z maxima starting before mid-January indicate a ridge comparable in strength to, but more persistent than, that in 2006. Just after mid-January, this ridge intensified further, leading to wave propagation that triggered the stratospheric vortex breakdown.

[8] The 2006 SSW, along with a similar event in 2004, was the strongest and longest-lasting on record [M08; Manney et al., 2005]. The diagnostics in Figure 1 show that the 2009 SSW surpassed that in 2006 and had a more profound and lasting effect on the lower stratosphere.

\section{Trace Gas Transport Observed by MLS}

[9] Vortex-averaged CO (Figure 2, top) indicates strong descent into the USLM vortex starting in fall, as is typical 


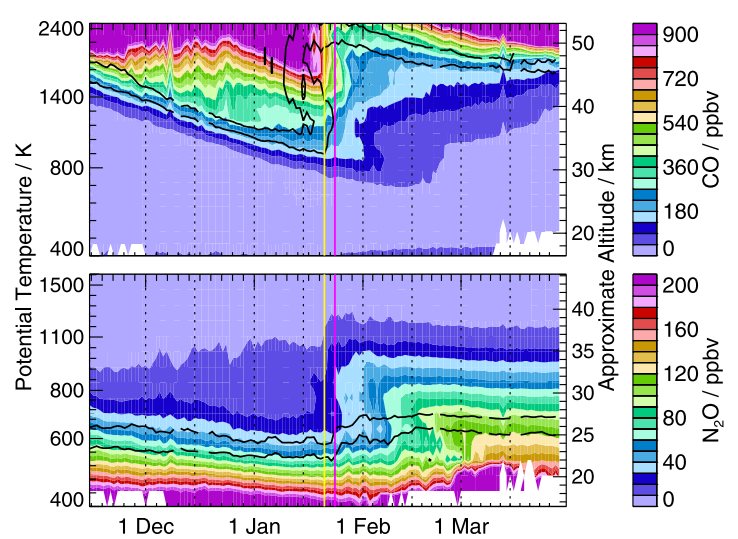

Figure 2. Vortex-averaged MLS (top) CO (400-2500 K) and (bottom) $\mathrm{N}_{2} \mathrm{O}(400-1600 \mathrm{~K})$ during the 2008-2009 winter. Overlaid contours are $\mathrm{CO}$ values of 270 and $540 \mathrm{ppbv}$ and $\mathrm{N}_{2} \mathrm{O}$ values of 60 and $90 \mathrm{ppbv}$ in 2005-2006. Yellow/ magenta lines show date major SSW criteria were fulfilled in 2006/2009.

(e.g., M09). Comparison with 2005-2006 (M09) shows that confined descent in December 2008 was weaker and less monotonic than that in December 2005, suggesting greater vortex variability in the upper stratosphere. In both years, CO decreased suddenly during the SSW as vortex air mixed with extra-vortex air. The $2009 \mathrm{CO}$ reduction was both more abrupt and less complete than that in 2006: CO began decreasing rapidly before mid-January 2006 at $\sim 40$ to $50 \mathrm{~km}$, then dropped suddenly at lower altitudes at the time of the vortex breakup. In 2009, the pattern of strong (albeit non-monotonic) descent was apparent through the time of the vortex split, after which it decreased suddenly at all levels above $\sim 35 \mathrm{~km}$. CO values of $\sim 135-225 \mathrm{ppbv}$ lingered at $40-45 \mathrm{~km}$ until mid-February after the 2009 SSW; CO values in that region just after the $2006 \mathrm{SSW}$ were $<90 \mathrm{ppbv}$ (M09).

[10] In the middle stratosphere, the signature of confined descent is seen in the downward progression of the $\mathrm{N}_{2} \mathrm{O}$ contours before the SSW (Figure 2, bottom). This descent was slightly stronger in 2009 than in 2006 below $\sim 600 \mathrm{~K}$ (compare $90 \mathrm{ppbv}$ contours) in December, suggesting a more quiescent lower stratospheric vortex at that time. A slight upward progression of the $\mathrm{N}_{2} \mathrm{O}$ contours began in early January 2006 (see also M09), indicating less complete confinement of vortex air. In contrast, in 2009, the downward progression of contours from confined descent continued until after the vortex split, when $\mathrm{N}_{2} \mathrm{O}$ dramatically increased between $\sim 500$ and $1000 \mathrm{~K}$, starting first at higher levels. The largest increases occurred several days after the vortex split, and were more sudden and of much greater magnitude than those in 2006.

[11] The vortex split on $\sim 20$ January in the upper stratosphere $(1700 \mathrm{~K}), \sim 24$ January in the midstratosphere $(850 \mathrm{~K})$, and $\sim 30$ January in the lower stratosphere $(520 \mathrm{~K})$ (Figure 3), consistent with the typical top-down development of SSWs. The MLS trace gas fields (Figure 3) clearly show material being drawn off the vortices as they decay at all levels (e.g., 28 January at $1700 \mathrm{~K}, 1$ February at $850 \mathrm{~K}$, 15 February at $520 \mathrm{~K}$ ). Largest decreases (increases) in high-EqL CO, $\mathrm{H}_{2} \mathrm{O}\left(\mathrm{N}_{2} \mathrm{O}\right)$ are associated, not with the vortex split, but with the subsequent decay and further fragmenting of the vortex remnants, $\sim 28$ January/1 February/15 February
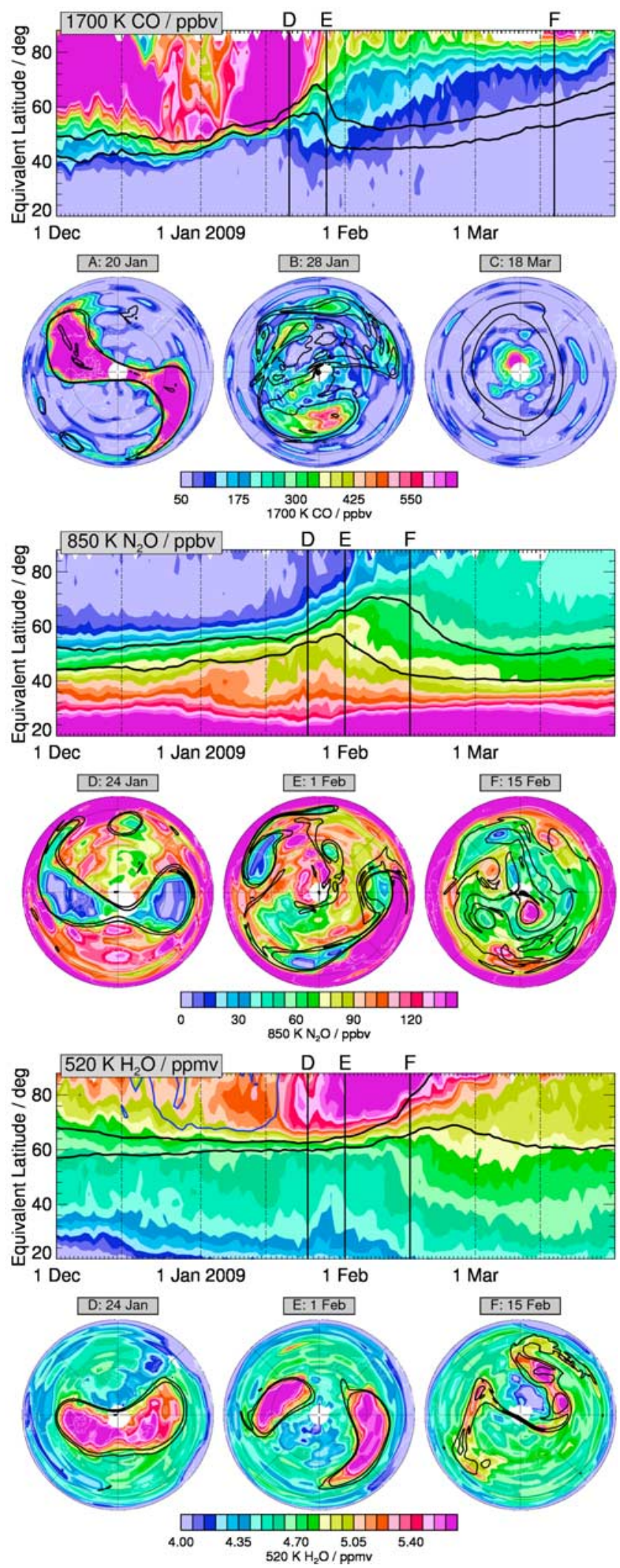

Figure 3. The (top) $1700 \mathrm{~K} \mathrm{CO}$, (middle) $850 \mathrm{~K} \mathrm{~N}_{2} \mathrm{O}$, and (bottom) $520 \mathrm{~K} \mathrm{H}_{2} \mathrm{O}$ equivalent latitude $(\mathrm{EqL}) /$ time series and maps on marked days. Black overlays are PV contours near the vortex edge. Maps show $0-90^{\circ} \mathrm{N}$, with $0^{\circ} \mathrm{E}$ at bottom, $90^{\circ} \mathrm{E}$ at right. Blue contours at $520 \mathrm{~K}$ are 190 and $195 \mathrm{~K}$ temperatures. 
at $1700 / 850 / 520 \mathrm{~K}$. This is in contrast to the vortex displacement event in 2006, during which tracer changes were more gradual and began before major SSW criteria were fulfilled.

[12] Descent of high mesospheric CO into the strong reformed vortex began almost immediately after the SSW (Figure 2); high $\mathrm{CO}$ reached the vortex core at $1700 \mathrm{~K}$ by $\sim 10$ March (e.g., 18 March map). This behavior is quite similar to that in 2006, except for the lingering slightly elevated $\mathrm{CO}$ values in the vortex core throughout the SSW.

[13] At $850 \mathrm{~K}$, the vortex was elongated after midJanuary, but not noticeably constricted into two lobes until 23 January (see http://mls.jpl.nasa.gov for daily maps), after which it rapidly split (Figure 3, 24 January map). The middle-stratospheric $\mathrm{N}_{2} \mathrm{O}$ decrease near $40^{\circ} \mathrm{EqL}$ after $\sim 15$ January is associated with tongues drawn off the vortex (e.g., 24 January map). Numerous small, well-defined, vortex and anticyclone remnants lingered for over a month after the SSW (1, 15 February maps). PV and $\mathrm{N}_{2} \mathrm{O}$ gradients tightened near $40-50^{\circ} \mathrm{EqL}$ starting in late February, indicating reestablishment of a (weak) vortex transport barrier. While the overall recovery was similar to that in 2006, the persistence of small, confined vortex and anticyclone remnants (with corresponding well-defined regions of low and high $\mathrm{N}_{2} \mathrm{O}$, respectively) was not apparent long after the SSW in 2006.

[14] At $520 \mathrm{~K}$, from $\sim 20$ January through $\sim 13$ February, tongues of tropical air were drawn up to very high latitudes (see maps), noticeably decreasing $40-60^{\circ} \mathrm{EqL} \mathrm{H}_{2} \mathrm{O}$. After mid-February, the $520 \mathrm{~K}$ vortex was virtually non-existent, though a small core of high $\mathrm{H}_{2} \mathrm{O}$ values lingered through early March. No significant recovery of the lower stratospheric vortex occurred after the SSW. Compared to the 2006 SSW, during which less complete vortex disappearance and slight recovery were seen, the impact of the 2009 SSW on the lower stratosphere was even more profound and prolonged. Before the SSW, temperatures were well below the threshold for polar stratospheric cloud (PSC) formation (blue contours in Figure 3) from mid-December through $\sim 24$ January. $\mathrm{MLS} \mathrm{ClO}, \mathrm{HCl}$ and $\mathrm{O}_{3}$ (not shown; daily maps available at http://mls.jpl.nasa.gov) indicate extensive chlorine activation and suggest chemical $\mathrm{O}_{3}$ loss during this period, enabled/enhanced by the vortex distortion bringing much of the PSC-processed air into sunlit regions. Early onset of chlorine activation and $\mathrm{O}_{3}$ loss subsequently curtailed by January SSWs has been observed in previous Arctic winters [Singleton et al., 2005; Santee et al., 2008].

\section{Summary}

[15] Aura MLS observations of temperature, geopotential height and trace gases make possible a comprehensive overview of dynamics and transport during the most prolonged and strongest major SSW on record, in January 2009. Previously observed intense SSWs in January were vortex displacement events, whereas the 2009 SSW split the vortex. Some features of the 2009 SSW were similar to those of the long-lasting SSW in January 2006: The stratopause dropped dramatically and broke down, then reformed at very high $(\sim 75-80 \mathrm{~km})$ altitude. This stratopause behavior was not well represented in GEOS-5 (and other) DAS analyses, in which observations provide direct constraints only up to $\sim 50 \mathrm{~km}$. Enhanced descent brought high $\mathrm{CO}$ down into an unusually strong reestablished USLM vortex. The middle stratospheric vortex reformed weakly. Other features of the 2009 SSW contrast with the behavior in 2006: There was a stronger geopotential height maximum in the lowermost stratosphere associated with forcing the 2009 SSW; winds reversed to easterly more rapidly, reverted to westerlies more slowly, and the reversal extended farther down into the upper troposphere/lower stratosphere. Trace gases were mixed out of the vortex rapidly, primarily during the decay of vortex fragments, after the $2009 \mathrm{SSW}$, as opposed to more gradually (beginning before the SSW) in 2006; except for a small lingering core of high $\mathrm{CO}$ in the upper stratosphere, mixing out of the vortex was more complete in 2009 than in 2006. More persistent well-defined fragments of vortex and anticyclone air were observed in 2009 than in 2006. The 2009 lower stratospheric vortex dissipated more completely than that in 2006 and showed no sign of recovery. More rapid wind reversal has previously been shown to be associated with vortex split than with vortex displacement events (CP07), and the synoptic evolution of the two large vortex fragments in 2009, with vortex air remaining largely well confined in each until after the split, suggests that differences in transport are also related to the differing character of the 2009 and 2006 SSWs. Extensive satellite observations of the 2006 and 2009 SSWs covering the upper troposphere through the mesosphere allow us to characterize these events in unprecedented detail. Further studies of these extreme events, including implications for stratospheric ozone loss and stratosphere-troposphere exchange, are in progress. Also under investigation are coupled circulation anomalies from the mesosphere through the troposphere (J. N. Lee et al., Aura Microwave Limb Sounder observations of the Northern Annular Mode: From the mesosphere to the upper troposphere, submitted to Geophysical Research Letters, 2009), effects of stratosphere-troposphere coupling on tropospheric weather, and the nature of the forcing.

[16] Acknowledgments. We thank the MLS Team for their support; NASA's GMAO for the GEOS-5 analyses; and Ken Minschwaner, Dong Wu, Doug Allen, and Michaela Hegglin for helpful discussions. Research at the Jet Propulsion Laboratory, California Institute of Technology, is done under contract with the National Aeronautics and Space Administration.

\section{References}

Andrews, D. G., J. R. Holton, and C. B. Leovy (1987), Middle Atmosphere Dynamics, 1st ed., Academic, San Diego, Calif.

Baldwin, M. P., and T. J. Dunkerton (2001), Stratospheric harbingers of anomalous weather regimes, Science, 294, 581-584.

Charlton, A. J., and L. M. Polvani (2007), A new look at stratospheric sudden warmings. Part I: Climatology and modeling benchmarks, J. Clim., 20, 449-469.

Charlton-Perez, A. J., L. M. Polvani, J. Austin, and F. Li (2008), The frequency and dynamics of stratospheric sudden warmings in the $21 \mathrm{st}$ century, J. Geophys. Res., 113, D16116, doi:10.1029/2007JD009571.

Coy, L., S. Eckermann, and K. Hoppel (2009), Planetary wave breaking and tropospheric forcing as seen in the stratospheric sudden warming of 2006, J. Atmos. Sci., 66, 495-507.

Labitzke, K. (1981), The amplification of height wave 1 in January 1979: A characteristic precondition for the major warming in February, Mon. Weather Rev., 109, 983-989.

Manney, G. L., K. Krüger, J. L. Sabutis, S. A. Sena, and S. Pawson (2005), The remarkable 2003-2004 winter and other recent warm winters in the Arctic stratosphere since the late 1990s, J. Geophys. Res., 110, D04107, doi:10.1029/2004JD005367.

Manney, G. L., et al. (2008a), The high Arctic in extreme winters: Vortex, temperature, and MLS trace gas evolution, Atmos. Chem. Phys., 8, 505-522. 
Manney, G. L., et al. (2008b), The evolution of the stratopause during the 2006 major warming: Satellite data and assimilated meteorological analyses, J. Geophys. Res., 113, D11115, doi:10.1029/2007JD009097.

Manney, G. L., et al. (2009), Satellite observations and modelling of transport in the upper troposphere through the lower mesosphere during the 2006 major stratospheric sudden warming, Atmos. Chem. Phys. Discuss., 9, 9693-9745.

Randall, C. E., V. L. Harvey, C. S. Singleton, P. F. Bernath, C. D. Boone, and J. U. Kozyra (2006), Enhanced $\mathrm{NO}_{x}$ in 2006 linked to strong upper stratospheric Arctic vortex, Geophys. Res. Lett., 33, L18811, doi:10.1029/ 2006GL027160.

Santee, M. L., I. A. MacKenzie, G. L. Manney, M. P. Chipperfield, P. F. Bernath, K. A. Walker, C. D. Boone, L. Froidevaux, N. J. Livesey, and J. W. Waters (2008), A study of stratospheric chlorine partitioning based on new satellite measurements and modeling, J. Geophys. Res., 113, D12307, doi:10.1029/2007JD009057.

Schwartz, M. J., et al. (2008), Validation of the Aura Microwave Limb Sounder temperature and geopotential height measurements, J. Geophys. Res., 113, D15S11, doi:10.1029/2007JD008783.
Singleton, C. S., et al. (2005), 2002-2003 Arctic loss deduced from POAM III satellite observations and SLIMCAT chemical transport model, Atmos. Chem. Phys., 5, 597-609.

Siskind, D. E., S. D. Eckermann, L. Coy, J. P. McCormack, and C. E. Randall (2007), On recent interannual variability of the Arctic winter mesosphere: Implications for tracer descent, Geophys. Res. Lett., 34, L09806, doi:10.1029/2007GL029293.

World Meteorological Organization (2007), Scientific assessment of stratospheric ozone depletion: 2006, U. N. Environ. Program, Geneva, Switzerland.

W. H. Daffer, R. A. Fuller, J. N. Lee, N. J. Livesey, G. L. Manney, M. L. Santee, and M. J. Schwartz, Jet Propulsion Laboratory, California Institute of Technology, Mail Stop 183-701, Pasadena, CA 91109, USA. (gloria.1. manney@jpl.nasa.gov)

K. Krüger, Leibniz Institute for Marine Sciences at Kiel University, Duesternbrooker Weg 20, D-24105 Kiel, Germany.

S. Pawson, NASA Goddard Space Flight Center, Mail Code 610.1, Greenbelt, MD 20771, USA. 